\title{
$\mathbb{1}$
}

\section{EN LOS DOBLECES DE LA REALIDAD - EXPLORACIONES NARRATIVAS. ESPAÑA: EOLAS EDICIONES (2019), DE ROSALBA CAMPRA}

André de Sena

\author{
André de Sena \\ Doutor e professor da Universidade Federal de \\ Pernambuco. \\ Idealizador e líder do Belvidera - Núcleo de Estudos \\ Oitocentistas e pesquisador dos grupos de pesquisa \\ Vertentes do Fantástico na Literatura e Núcleo de \\ Estudos sobre Gêneros. \\ http://lattes.cnpq.br/9977565773182194 \\ https://orcid.org/0000-0003-2090-6398 \\ andredesena.art@gmail.com
}


Os estudiosos e leitores de literatura fantástica comemoraram o lançamento do novo livro da escritora e pesquisadora argentina Rosalba Campra, En los dobleces de la realidad - exploraciones narrativas (Eolas Ediciones, 2019), que veio a lume cerca de uma década depois do - agora já clássico - Territorios de la ficción. Lo fantástico (Renacimiento, 2008) $)^{1}$, cuja tradução/edição brasileira

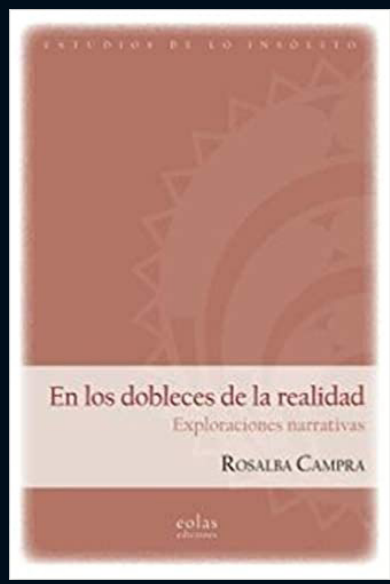
saiu pela editora Dialogarts em 2016, organizada por um rico time de especialistas da Universidade Estadual do Rio de Janeiro².

Isso não quer dizer que a autora se manteve em silêncio em todos esses anos. Ao contrário, publicou diversas obras ficcionais, a exemplo de Mínima mitológica (2011), Las puertas de Casiopea (2013), Ficciones desmedidas (2015); livros de poemas como Arqueología provisoria (2018), e de viés intersemiótico, em Moradas de los Mayores (2012); bem como a obra metacrítica de fôlego Itinerarios en la crítica hispanoamericana (2014), sem olvidar toda a intensa atividade docente como professora e orientadora em sua cátedra de literatura hispanoamericana na Sapienza Università di Roma, e palestrante em universidades de referência pelo mundo. Mas o que todos nós, apaixonados pela literatura insólita, realmente estávamos esperando, era um novo aporte teórico sobre a ficção imaginativa, que

1 Versão definitiva, revisada e com acréscimos, da obra original escrita em italiano, Territori della finzione. II fantastico in letteratura, publicada no ano 2000.

2 CAMPRA, Rosalba. Territórios da ficção fantástica. Rio de Janeiro: Dialogarts Publicações, 2016. 
agora se materializa, nas mesmas pegadas de Territorios de la ficcion. Lo fantástico, essa obra de referência que serviu a um tempo de compêndio crítico - sem que esta tenha sido sua intencionalidade primeira - referente a quase tudo que se escreveu sobre o tema anteriormente, e estudo atualizador comparativista, com efetivas contribuições teóricas, a respeito do que passou a existir, em termos ficcionais e críticos, da segunda metade do século $X X$ à contemporaneidade. Em outras palavras, Campra reatualizou os estudos sobre o fantástico nessa obra, sempre problematizando as leituras críticas - a sua própria, inclusive - a partir de análises exemplares e uma escrita envolvente, leve e acessível, que não precisa apelar para os bizantinismos conceituais, a respeito não apenas desse fenômeno tão polissêmico que é o fantástico, mas dos procedimentos artísticos da literatura como um todo.

En los dobleces de la realidad - exploraciones narrativas traz o mesmo formato ensaístico dessa obra anterior, cada capítulo enfocando uma perspectiva de leitura e objetos ficcionais distintos num continuum que, ao final, revela a organicidade do todo, tendose sempre em vista a compreensão do que Campra define, logo na introdução, como "efeito fantástico", a saber: "la postulación de la realidad como un fenómeno múltiple y escurridizo, cuyos contornos se precisan o se borronean según la capacidad (¿la voluntad? ¿el deseo?) de percibirlos de un sujeto (¿el personaje? ¿el lector?)." ${ }^{\prime 3}$ (CAMPRA, 2019, p. 16).

3 "A postulação da realidade como um fenômeno múltiplo e escorregadio, cujos contornos se precisam ou se borram segundo a capacidade (a vontade? o desejo?) de um sujeito em percebê-los (o personagem? o leitor?)". Todas as traduções do espanhol ao português a partir daqui serão nossas. 
O banquete teórico começa não com uma simples entrada ou petisco, mas já com um prato principal, no capítulo de abertura "Descartar, seleccionar, clasificar. ¿Qué hacer con las sirenas?", em que a ambiguidade das classificações (quando não, das próprias palavras) é tomada metaforicamente à imagem das sereias: apesar de, em seu pragmatismo, as palavras terem o condão logocêntrico de imprimir ordem ao caos do universo empírico (como os rótulos e as classificações com que talvez o sobrepesemos ainda mais), por vezes - e de maneira autoconsciente -, agem noutra perspectiva e contrariamente, expondo sua sedução pela 'desorganização', como a que o fantástico impõe ao universo diegético, tão 'perigosa' esta última, a ponto de poder talvez sair do limite das páginas dos livros e se espraiar pela realidade. Pois a recepção literária, desde a obra Territorios, é uma das principais preocupações das análises de Campra, que incita-nos a refletir como os gêneros, modos e categorias estão essencialmente configurados de acordo (ou numa espécie de 'desacordo' tácito aceito, típico do fantástico e do que dele esperam seus leitores) com os atos de leitura em toda sua complexidade. É dessa dinâmica que ressumbra o fantasma da classificação, tema desse primeiro capítulo, a partir do estudo de três narrativas: "La Sirena", conto do livro Misteriosa Buenos Aires (1951), de Manuel Mujica Lainez; "Lighea" (1961, publicação póstuma), de Giuseppe Tomasi di Lampedusa; e "The Blind Pilot" (1959), de Damon Knight, Nathalie e Charles Henneberg. Tomando como base, numa interessante analogia, as maneiras pelas quais os biólogos e botânicos classificam seus espécimens, Campra busca deslindar os intertextos, as diversas

4 "Descartar, selecionar, classificar. O que fazer com as sereias?". 
semelhanças e dessemelhanças entre eles, relembrando ainda as dinâmicas de alteridade entre os gêneros e as obras - algo semelhante ao que se diz no capítulo introdutório de Introdução à literatura fantástica (1970), de Todorov, em que o processo também é elencado, mas na perspectiva formalista: "Siendo un sistema una interdependencia en devenir, cada nuevo texto redefine los bordes y la situación relativa de los otros elementos del sistema." ${ }^{5}$ (CAMPRA, 2019, p. 39). Por sua vez, Campra insere a dimensão receptiva como fundamental ao processo, já que o leitor condiciona e/ou desautomatiza sua própria imersão no texto (ou numa memória coletiva que por vezes vai além deste) - no caso desse capítulo, relativa a arquetípica imagéticoconceitual das sereias - a experienciações estéticas prévias. $\mathrm{Na}$ reinvenção (ou não) do imaginário das sereias, e através de um profissional trabalho comparativista, Campra realiza um grande ato de orquestração analítica, ressaltando ainda, poeticamente, a beleza semântica desses três contos, ao tempo que, com pinça sutil, revela aos olhos dos críticos os mecanismos e procedimentos ocultos ou ocultados por seus autores. De acordo com a plasmação desses seres híbridos dentro de contextos diegéticos específicos, mas síncronos em temas ou motivos (o bifrontismo do canto, a fatalidade boa ou má, o cronotopo marinho etc.), poder-se-ia ou não afirmar a homologação ou a arbitrariedade dos três contos como pertencentes a uma tipologia específica? É quando se pergunta a autora:

Porque, cabe preguntarse, ċla distinción entre uno y otro tipo de objetos depende del cuento en que

5 "Sendo um sistema uma interdependência em devir, cada novo texto redefine as bordas e a situação relacional de seus outros elementos". 
estén? ¿O es más bien el objeto quien impone la clasificación del cuento? Tal vez no haya una cosa que en sí cree lo fantástico ni, quizá, situación que en sí lo sea, sino que se trate de una red tejida por el análisis - en que cada cosa puede ser detenida por un nudo de la malla, que nos permite recuperarla de la fluencia y proponerle un sentido: una dirección de lectura. En referencia a nuestros relatos, ¿qué clase de objeto es la sirena? ¿Fabuloso? ¿Fantástico? ¿Fantacientífico? ${ }^{6}$ (CAMPRA, 2019, p. 46-47)

A Grand ouverture do primeiro capítulo do novo livro de Campra chega ao seu acme com a implementação desse paradoxo genológico que continua a lhe 'vampirizar' - como ela própria afirmara no prólogo de En los dobleces, em relação à aporia fantástica que parece ter saído das páginas de Territorios de la ficcion e se instituído como inquietação a respeito do modo fantástico literário: "Los fantasmas siguieron reclamando mi atención, la abismal fascinación de los vampiros no sufrió mengua $[. . .]^{\prime \prime 7}$ (CAMPRA, 2019, p. 13). E é pelo caminho das aporias que o fantástico se distende, como um efeito gerado a partir de uma série de inter-relações que Campra evidencia em análises que vão ao âmago da questão (focalização, voz narrativa, modalização, intertextualidade, organização do texto, recepção/campo literário etc.), revelando-nos como essa modalidade se perfaz

6 "Porque, alguém se pergunta, a distinção entre um tipo de objeto e outro depende da narrativa em que eles estão? Ou é antes o objeto que impõe sua classificação? Talvez não haja nada que por si crie o fantástico, nem, talvez, uma situação que por si só o seja, mas se trate de uma rede - entretecida pela análise - em que cada coisa pode ser retida por um nó na malha, que nos permite resgatá-la do fluxo e lhe propor um sentido: uma direção de leitura. Em referência às nossas narrativas, que tipo de objeto é a sereia? Fabuloso? Fantástico? Fantacientífico?"

7 "Os fantasmas continuaram a chamar minha atenção, o fascínio abismal dos vampiros não diminuiu". 
na obliquidade da referencialização e num jogo sinuoso bem mais complexo do que o que se joga noutras séries, modos e/ou subgêneros mais ou menos miméticos, através de "distorsiones sutiles de su propio objeto"8 (CAMPRA, 2019, p. 52).

Após o exorcismo, ou melhor, a catarse criativa na busca pela essência e a nominação dos demônios da classificação do primeiro capítulo, chega-se ao segundo, “¿De dónde vienen los fantasmas? ¿Y hacia dónde van?" ${ }^{\prime 9}$, outra fina iguaria em que, inicialmente, por meio de leituras de cunho psicocrítico e genético, a autora busca deslindar as camadas de sugestões, possíveis significações e procedimentos retórico-estilísticos de "Axolotl", de Julio Cortázar, reiterando na verdade a leitura desse mesmo conto desenvolvida em Territórios. A inquietação aqui é referente à necessária verossimilhança dentro do fantástico, ou seja, como tornar crível o fenômeno insólito que se estabelece através das relações entre personagens, escritura e leitor? Como os atos enunciativos podem ou não delimitá-lo, ou mesmo abarcá-lo razoavelmente, sem que se quebre com isso aquela 'verossimilhança interna' típica do modo fantástico, que vai léguas além dos padrões aristotélico-horacianos? Entra na discussão o que Campra (2019, p. 79) bem cognomina de metadiscursividade na produção do efeito fantástico, a abranger e anfibolizar isotopias distintas, no sentido de que a abertura proporcionada por este modo é diversa da polissemia 'tradicional' dos textos literários miméticos, ao se exigir uma espécie de 'desautomatização em segundo grau', estando o primeiro desses graus apenso à própria 'literatura'.

8 "Distorções sutis de seu próprio objeto".

9 "De onde vêm os fantasmas? E para onde eles vão?" 
Metaliteratura, em outras palavras; e talvez com algo de barroco também, nesse jogo de se revelar e ocultar a um tempo. Doutra monta, no último dos três subcapítulos que enformam o segundo capítulo, intitulado "Arquetipos y variaciones"10, observa-se todo um lastro de sociocrítica, revelando-se-nos com essa nova perspectiva que ao modo fantástico não se recusa a leitura semântica, a busca por prováveis raízes empíricas e históricas (ou as possibilidades analíticas no que toca a esses horizontes) a muitas de suas fábulas, em diversos exemplos discutidos.

Por sua vez, pode-se observar em "Leer ficciones. Condiciones y consecuencias"11, terceiro capítulo de En los dobleces, um texto seminal, por exemplo, para se trabalhar com alunos numa aula sobre teoria da literatura (e não só fantástica) a partir da estética da recepção, o leitor emergindo como um dos baluartes da significação, um vero "'constructor' de sentido[s]"12 (CAMPRA, 2019, p. 106), na expressão da autora. Não sendo um mero receptáculo passivo, especialmente quando se defronta com a, de per se hipostasiada, semântica de um texto fantástico, envida, no geral, uma "ardua tarea"13 (CAMPRA, 2019, p. 107). Campra discorre sobre algumas escolas, autores e teóricos que desenvolveram ao longo das décadas propostas de leitura do texto literário a partir do tema da recepção (New Criticism, semiologia, fenomenologia, Crítica da leitura etc.), problematizando cada uma delas. E ao fim nos revela a historicidade tanto do leitor como dos textos:

10 "Arquétipos e variações".

11 "Ler ficções. Condições e consequências".

12 "Construtor de sentido[s]".

13 "Árdua tarefa". 
Las lecturas son tan epocales como la escritura. Sabemos que cada circunstancia histórica hace que determinados textos, contemporáneos 0 no del lector, se descifren como esclarecimiento de momentos precisos. Un ejemplo: la violencia $y$ el terror vividos en Argentina entre los años setenta y ochenta del siglo XX han provocado una decodificación unidireccional de los textos de esos años como una referencia a la dictadura. ${ }^{14}$ (CAMPRA, 2019, p. 108-109)

Por outro lado, há variações ainda mais profundas que podem ir muitos passos adiante do que se espera dos cronotopos, diacronias e sincronias, nos fecundos territórios da subjetividade, como Campra também tem o cuidado de ressaltar, de certa forma uma recusa a uma arquetípica do leitor implícito:

El problema consiste en que, al hablar del lector, se habla de un supuesto del texto: una necesaria generalización. Pero en la lectura como experiencia - relación con un libro - existen los lectores. Plurales, concretos, pertenecientes a un espacio y un tiempo cada vez diferentes. Lectores femeninos, masculinos, doctos, ingenuos, contemporáneos del texto, separados del texto por el transcurso de los siglos. Lectores que, además, no solo forman parte de la Historia, sino que tienen su propia historia.

Lo que crea el desafío teórico es esa diacronía individual que hace que el mismo lector no vuelva a leer dos veces el mismo libro: el mismo libro, en una nueva lectura, es un libro diferente. La acumulación de vivencias que llevan, por ejemplo, de la adolescencia a la madurez determina, entre

14 "As leituras são tão epocais quanto a escrita. Sabemos que cada circunstância histórica faz com que certos textos, contemporâneos ou não do leitor, sejam decifrados como revelações de momentos precisos. Um exemplo: a violência e o terror vividos na Argentina entre os anos setenta e oitenta do século XX causaram uma decodificação unidirecional dos textos daqueles anos como referência à ditadura". 
otras más dramáticas variaciones, las variaciones de actitud y de respuesta - sería mejor decir pregunta - frente a un texto. Determina otra identidad de lector. Tal vez una de las falencias de la crítica de la lectura nazca precisamente de su oscilación entre un concepto de lector absolutamente genérico, transhistórico, y una apoyatura en lo individual, lo subjetivo [...]. ${ }^{15}$ (CAMPRA, 2019, p. 110-111, grifo da autora)

Tal dimensão receptiva não é, contudo, exponenciada numa 'abertura total', já que é na relação com as supostas intencionalidades prévias ao texto, além de seus constituintes propriamente ditos, que se estabelecerão as marcas do fantástico. Essa leitura enriquece o estudo do fantástico, ao ampliar a anterior visão genológica que o confrangia aos simples embates entre o sobrenatural e o real - e às escolhas ou gradações entre um e outro dentro de certas convenções apriorísticas -, e ao levar em consideração diversos fatores tanto de ordem sociohistórica, psicocrítica, biográfica, como formais, estilísticos, modais, intertextuais e receptivos. Assim, com tantos vetores em jogo para que o efeito fantástico seja plasmado, como que

15 "O problema é que, ao falar do leitor, fala-se de um pressuposto do texto: uma generalização necessária. Mas na leitura como experiência - em relação a um livro existem os leitores. Plurais, concretos, pertencentes a um espaço e um tempo sempre diversos. Leitores femininos, masculinos, eruditos, ingênuos, contemporâneos do texto, separados do texto no transcurso dos séculos. Leitores que, além disso, não só fazem parte da história, mas também têm sua própria história. O que cria o desafio teórico é essa diacronia individual que impede o mesmo leitor de reler o mesmo livro duas vezes: o mesmo livro, em uma nova leitura, é um livro diferente. O acúmulo de experiências que levam, por exemplo, da adolescência à maturidade determina, entre outras variações mais dramáticas, variações de atitude e resposta - seria melhor dizer uma pergunta - diante de um texto. Determine a identidade de outro leitor. Talvez uma das deficiências da crítica da leitura decorra justamente de sua oscilação entre um conceito de leitor absolutamente genérico, transhistórico, e uma nominação do individual, do subjetivo [...]". 
se autentica o que certa vez escreveu o contista Braulio Tavares (2003, p. 8): "Cada conto fantástico nos revela não apenas uma nova descoberta, mas uma nova maneira de descobrir".

O quarto capítulo, "El relato de sueños. ¿Qué clase de tejido es un texto?"16, é um dos mais instigantes de En los dobleces, por conta da maneira inovadora com que a autora aborda a expressão do fantástico. A partir do que Campra (2019, p. 125) define como "inenarrabilidad" e "inexplicabilidad"17 dos fenômenos oníricos, e das descrições dos mesmos desenvolvidas em narrativas diversas, ou seja, as maneiras pelas quais se narram os sonhos 'reais' e de como tais procedimentos podem se aproximar dos recursos do fantástico literário, o capítulo retoma uma temática bastante cara aos primórdios dessa modalidade nos albores do movimento romântico. Falo aqui daquele imaginário ficcional e de campo literário trabalhado em obras clássicas como, por exemplo, L'âme romantique et le rêve: essai sur le romantisme allemand et la poésie française (1937), de Albert Béguin, a revelar toda a importância que os sonhos exerceram nas pioneiras obras do romantismo alemão e sua posterior influência na França oitocentista. Só que Campra atualiza esse imaginário, ao trabalhar com excertos de autores contemporâneos, como Cortázar, Roberto Bolaño, Carlos Gamerro, William Gibson, a poeta Silvia Barei, os quadrinhos de Tiziano Sclavi e Giovanni Freghieri, dentre outros artistas (especialmente das artes visuais e fotografia), além de a própria autora narrar experiências oníricas pessoais. Segundo Campra,

16 "O relato de sonhos. Que tipo de tecido é um texto?"

17 "Inenarrabilidade", "Inexplicabilidade". 
creo que el sueño (mejor dicho el relato de un sueño) se distingue de otros tipos de relato solo porque se le supone un sentido que no reside en la información sobre algo que sucede o sucedió (documental o ficcional), sino en un reenvío (necesariamente metafórico) a algo que está en otro lugar de la significación. Supongamos una narración así de simple: "Me senté en la terraza y desayuné un jugo de naranjas, café, arenque ahumado con cebolla y tostadas. El pan se me había quemado".

No es necesario subrayar lo distinto que resulta el texto si se trata de una confesión a un dietólogo sobre determinados hábitos alimenticios o de un sueño que se cuenta a un psicoanalista. El texto es siempre el mismo, pero en el segundo caso habría que ver por qué los arenques, por qué el pan quemado: la pregunta artera y peligrosa, ¿qué quiere decir? Lo que crea la diferencia es el tipo de interrogación que supone el segundo caso, tendiente a la búsqueda del sentido 'verdadero' de lo que se narra, como si el sueño adoleciera de una incompletud. ${ }^{18}$ (CAMPRA, 2019, p. 132-133)

Dessarte, a organização, ou sentido ontológico que se dá a uma descrição de sonho no universo empírico pode se aproximar mais ou menos dos graus do fantástico, como afirmado, bem

18 "Acho que o sonho (ou melhor, o relato de um sonho) se distingue de outros tipos de relato apenas porque é assumido um significado que não reside na informação sobre algo que acontece ou aconteceu (documental ou ficcional), mas em um encaminhamento (necessariamente metafórico) para algo que está em outro lugar na significação. Suponhamos uma narração tão simples como esta: 'Sentei-me na varanda e tomei um suco de laranja, café, arenque defumado com cebola e torradas ao desjejum. Meu pão estava queimado'. Não é necessário enfatizar o quão diferente é o texto se for uma confissão a uma nutricionista sobre certos hábitos alimentares ou um sonho que é contado a um psicanalista. O texto é sempre o mesmo, mas no segundo caso seria necessário ver por que o arenque, por que o pão queimado: a pergunta furtiva e perigosa: o que significa? O que faz a diferença é o tipo de interrogação que o segundo caso supõe, tendendo à busca do sentido 'verdadeiro' do que é narrado, como se o sonho sofresse de uma incompletude". 
como de modalidades/gêneros afins como o realismo mágico, os contos de fadas etc., segundo nos revela a autora, saindo do horizonte temático trabalhando por Béguin (na perspectiva biografista, especialmente) e adentrando o universo da escrita propriamente dita, sendo esta sua contribuição. Um dos melhores momentos do livro é quando a autora se propõe, a partir de estampas japonesas dos séculos XVIII e XIX, a uma análise semiótica de representações dos sonhos, estabelecendo liames com outras de mesmo tipo desenvolvidas pela escrita, focando ora a superposição de planos, ora a dissociação, ora o amálgama (aparente ou sugestivo) entre eles.

Se muito da própria autora e sua visão particular da literatura e do fantástico perpassou de forma 'subjetiva' - mas nunca impressionista, cumpre ressaltar - os quatro primeiros capítulos de En los dobleces, no quinto e último, "El envés de lo leído: desde el lugar de la escritura"19, temos um verdadeiro cadinho memorialista, a um tempo teórico e metaficcional, em que Campra nos revela sua própria experiência com o fantástico, enquanto leitora e escritora. Também se configura como um importante documento sobre suas obras ficcionais, e a relação de maior ou menor proximidade com o fantástico, a alegoria, o mítico, o realismo esgarçado pela memória etc., que estas demandam. No limite, discute possíveis dicotomias existentes entre os que são a um tempo autores e críticos/teóricos, com a ulterior recusa das mesmas, já que, como defende:

[...] la escritura abarca múltiples voces, sin jerarquías ni vallas. Esto no quita que subsistan diferencias: de lo que 'acontece' en mi trabajo crítico soy responsable en primera persona; de los

19 "O reverso do que é lido: do lugar da escrita". 
acontecimientos de un relato, la responsabilidad compete a quienquiera los viva - esos seres de ficción que llamamos 'personajes' - y a quien quiera pertenezca la voz que los relata - una voz ficcional $[. . .]^{20}$ (CAMPRA, 2019, p. 188)

Tem-se, logo em seguida, algo como uma cartografia, ou melhor, um guia de 'viagem' relativo à ficcionalidade fantástica, numa perspectiva que revela sem conflitos sua experiência dupla de ficcionista e teórica, quase em um 'desdobramento de personalidade' que parece criar não um duplo mas um 'triplo' da própria Rosalba Campra, a analisar objetivamente essa referida experiência também através do cotejo entre diversas tipologias, categorias e procedimentos (insólito segundo ciências, ideologias etc.; situação histórica; dispositivo retórico [discurso]; insólito como ruptura, mas organizado segundo modos 'sólitos'; relato sólito, mas com retórica insólita; graus, modalizações, desvios; manifestações do extraordinário [verdadeiramente extraordinário, acidental e fraudulento]; ironia; paraliteratura etc.). Atente-se que não se busca com tais termos a criação de uma 'teoria do fantástico' específica, mas discussões tópicas sobre artefatos ficcionais distintos que parecem, cada um à sua maneira e ao fim e ao cabo, sugerir-nos novamente a proteiformidade como um dos caracteres essenciais do fantástico. Trata-se de um rico repositório analítico através do qual Campra nos segreda suas próprias perplexidades teóricas acerca dessa modalidade, ao tempo que conduz-nos com segurança em meio à selva oscura das significações e/ou meia significações, 20 "[...] a escrita engloba múltiplas vozes, sem hierarquias ou cercas. Isso não significa que não existam diferenças: no que 'acontece' em meu trabalho crítico, sou responsável em primeira pessoa; dos eventos de uma história, a responsabilidade recai sobre quem os vive - aqueles seres fictícios que chamamos de 'personagens' - e quem quer que seja a voz que os narra - uma voz fictícia [...]". 
sem nos deixar cair em armadilhas apriorísticas. E realiza tudo isso, como afirmado, também incorporando ao material estudado os seus próprios contos, o que abre uma janela extra de interesse para fechar o banquete com rico pospasto.

Apesar de todos esses diversificados olhares, que fazem rebrilhar o fantástico sob novas quadraturas expositivas e analíticas, Campra está ainda a nos 'dever' um olhar mais atento a um ponto específico de análise até o momento não desenvolvido, seja em Territorios de la ficción. Lo fantástico ou em En los dobleces de la realidad - exploraciones narrativas, a saber: as possíveis relações e diferenças entre o fantástico e o horror. Numa passagem do último capítulo desta mais recente obra, citando um trecho da crítica Ana María Morales ("Fuera de la legalidad aceptada dentro del sistema textual, lo fantástico se presenta como un acontecer ilegal y transgresor" ${ }^{21}$ [p. 186-187]), Campra sugeria a porta que talvez eu particularmente esperasse, no sentido de que ela pudesse aprofundar mais esse aspecto 'negativo' que muitos autores associam ao fantástico mas que é, outrossim, típico do horror. As abordagens sobre essa relação variam bastante entre os estudiosos, ainda antes de Todorov, que, por sinal, diferencia o fantástico do horror sem aprofundamentos, chegando a convidar os leitores que se interessassem especificamente por este último a ler o ensaio lovecraftiano 0 horror sobrenatural em literatura. Contudo, na perspectiva pós-todoroviana, que também é a de Campra, quando o fantástico passa a ser compreendido como uma modalidade, repensam-se as suas relações com a alegoria,

21 "Fora da legalidade aceita dentro do sistema textual, o fantástico é apresentado como evento ilegal e transgressivo". 
a poesia, o símbolo e o maravilhoso, bem como o horror. Fica a sugestão para um próximo ensaio, visto que em Los dobleces há um momento importante em que o riso (e, nas entrelinhas, o grotesco) é evocado em seus possíveis imbricamentos com o modo fantástico. Falta apenas inserir agora a cor do medo estético e literário para completar sua paleta crítica.

\section{REFERÊNCIAS}

CAMPRA, Rosalba. En los dobleces de la realidad - exploraciones narrativas. España: Eolas Ediciones, 2019.

CAMPRA, Rosalba. Territórios da ficção fantástica. Rio de Janeiro: Dialogarts, 2016.

TAVARES, Braulio. Nas periferias do real ou o fantástico e seus arredores. In: TAVARES, Braulio (Org.). Páginas de sombra: contos fantásticos brasileiros. Rio de Janeiro: Casa da Palavra, p. 7-18, 2003.

TODOROV, Tzvetan. Introdução à literatura fantástica. 3.ed. São Paulo:

Perspectiva, 2007. 